family are discussed, although this would surely be done anyway before embarking on compulsory treatment.

Ethical issues surrounding behavioural treatment are discussed, emphasising the relative lack of research on treatment outcome in anorexia nervosa. The authors are critical of the standard behavioural programmes that used to be popular in treating eating disorders. They advocate the use of a brief reward programme to enable weight gain from a life-threatening low weight, although as yet no research is available to support the use of this model.

Finally, the chapters on health care set the dilemmas in context by highlighting the difficulties in providing treatment for eating disorders within a context of rationing. Ethics and market forces are discussed well, particularly in relation to the treatment of eating disorders within the context of managed care in the US.

In summary, this is a readable and well-considered book which I would recommend to those interested in the ethical issues arising from treatment of eating disorders. This is a highly relevant and controversial area and the book provides a useful contribution to the debate.

ANNE STEWART

Consultant Adolescent Psychiatrist Highfield Family and Adolescent Unit, Warneford Hospital, Oxford

\section{Healing Dramas and Clinical Plots. The Narrative Structure of Experience}

\author{
Cheryl Mattingly, Cambridge, \\ Cambridge University Press, 1998, \\ 191 pages, $£ 14.95$ (sc).
}

Cheryl Mattingly is an anthropologist who has studied the practice of occupational therapists in Boston, Chicago and Los Angeles over the decade beginning 1986. Previous reports of the studies, particularly those dealing with narrative reasoning, have been published in books and journals. This new book on healing dramas is a drawing together of themes from previous research, and brings to the reader the resulting theoretical insights which Mattingly has developed during the course of this major ethnographic study. The purpose of the book is to describe an "ethnography of occupational therapy" focusing on therapeutic narrative, with a parallel discourse on the relationship between "narrative, action, and experience". To achieve this Mattingly relates her material to key thinkers in anthropology and philosophy including Ricoeur, Geertz, Heidegger and Dilthey. Mattingly writes movingly about the experience of disability and long term illness, and how narrative is used by the therapist to understand the patient's previous life and to build on that understanding to create future life opportunities.

Three major themes run through the book:

i. The author's experience of carrying out the studies, in particular her relationship with the therapists and their patients.

ii. The way in which narrative analysis could be used to make sense of the therapeutic encounters.

iii. The potential for theory development from the narrative analysis.

The book is written using a narrative structure, with a major story being the researcher's experiences. In addition there are a series of sub-stories which include: finding a narrative; what narrative means; understanding and interpreting narrative, and the relationship of story to self.

While the book is not written particularly with ethicists in mind, the whole focus of the content is about behaving well in the clinical setting. Mattingly writes that when considering morality in this setting the whole process "carries a moral resonance". This is translated in practical terms into the negotiation of the moral when working towards quality of life with people who have permanent disabilities. The potential for negotiation between health workers and their patients is seen to be more risky in fast track medical care where communication failures are most likely, when compared to slow track therapy where both more formal and informal time can be spent with the patient.

As an occupational therapist I was charmed and stimulated by the insights which the book sheds on day-to-day practice. Mattingly reminded me that not everyone is comfortable when communicating with people who have severe physical, intellectual or psychological illness, and refers to complex impairments as "biomedical disaster areas". She describes her need on occasion to leave the treatment room when faced with severe suffering, and admired the occupational therapists who routinely showed care and compassion. Mattingly also explores her lack of valuing of women's roles before undertaking this research, during which she had to review the world of women and domestic activity. She was eventually able to accept that housework and homemaking are central cultural concerns in patients' lives.

While much of the book describes the familiar face of occupational therapy, I was disconcerted by the concentration on the "clinical setting", and the use of language which included the words "patient", "illness", and "diagnosis". Many occupational therapists work in social and community settings where the medical model and application would not be seen as relevant to their practice. Mattingly's exploration of narrative in therapeutic encounters, and theoretical explanation of events is masterly. She starts her argument with the statement that "narratives are not just about experiences", but that narrative is created out of action, and fulfils a variety of other purposes. These include helping to shape the future, and exploring alternative ways of planning activities. Mattingly sees narrative as drama which is used in occupational therapy to lead to the "creation of desire". When working with people with disabilities failure was seen to arise when the patient did not "embrace the recuperative journey which involves adapting to one's new (disabled) body...".

At a time when virtue ethics are back on the ethical agenda, this book has a great deal to say about the virtuous occupational therapist and by association, other health care workers. Mattingly refers to the evangelical streak she saw in the therapists she observed, and to the moral issues which arose when the therapists penetrated the inner consciousness of their patients.

Occupational therapists worry that their skills are often seen as mundane and lacking the trappings of sophisticated technology or potential for major medical dramas. This book provides a celebration of ordinariness, "the ritual of the everyday", and uncovers the flexibility and complexity of therapy where the only tools the therapist has are herself and objects in her and her patient's immediate environment.

\section{ROSEMARY BARNITT}

School of Occupational Therapy and Physiotherapy, University of Southampton 